den Seiten mit feinen Querrunzeln; Clipeus wie bei huberi; Antenne kurz und dick. Thorax gröfstenteils matt und dicht runzlig punktiert. Scutum vorn und seitlich, Scutellum in der Mitte glatt, stark glänzend, sonst längsgestreift; Epinotum dicht punktiert, mit sehr schwachen Spuren von Zähnen, Basalfläche flach; Postpetiolus queroval. Flügel fehlen. - L. $3,5 \mathrm{~mm}$.

Die Beschreibung bezieht sich auf die Grundform:

Str. afer afer Emery.

Daya in West-Algerien; nach einem einzigen Exemplar beschrieben.

Eine andere Unterart kommt in Spanien vor.

Str. afer caeciliae For.

Ann. Soc. ent. Belgique v. 41, p. 132. 1897.

ㅇ (nach Forel). Diese Form zeichnet sich durch flache Augen und gewölbte Basalfläche des Epinotum aus.

Das $\sigma^{7}$ ist (nach F o r e l) 3,7 mm lang; differiert von $S$. huberi durch seinen viel weniger nach hinten verschmälerten Kopf, und durch den Petiolusknoten, der in seinem hinteren Drittel viel erhabener ist und einen oberen, in der Mitte ausgeschnittenen Rand bildet.

\title{
Systematische und synonymische Notizen über Lagriiden und Alleculiden. (Col.)
}

Von F. Borchmann, Hamburg.

Bei der Bearbeitung der mir übertragenen Familien für den neuen "Catalogus Coleopterorum" haben sich verschiedene Änderungen als wünschenswert oder notwendig herausgestellt, zunächst eine Einteilung der Lagriiden in neue Unterfamilien, die hier kurz aufgeführt und charakterisiert sein mögen.

1. Trachelosteninae. Die Vertreter dieser Unterfamilie schliefsen sich den Tenebrioniden am nächsten an. Ihre Vorderhüften stofsen nicht aneinander, das vorletzte Tarsenglied ist nicht ausgerandet, höchstens gerade abgestutzt, das Endglied der Fühler nicht auffallend verlängert, das Endglied der Maxillartaster stark beilförmig und der Körper gestreckt. 
2. Lagriinae. Die Vorderhüften stofsen aneinander, weil das Prosternum zwischen ihnen nicht erhaben ist. Das vorletzte Fufsglied ist an allen Füfsen stark verbreitert und ausgerandet, das Endglied der Fühler meist auffallend verlängert. Der Abstand der Augen ist unterseits des Kopfes bedeutend gröfser als oberseits, Endglied der Maxillartaster dreieckig, Körper meist gedrungen.

3. Statirinae. Die Ângehörigen dieser Unterfamilie haben durch deutlich erhabenes Prosternum getrennte Vorderhüften, ausgerandetes vorletztes Fufsglied, stark verlängertes Endglied der Fühler, dreieckiges Endglied der Maxillartaster, meist grofse Augen, deren Abstand an der Unterseite des Kopfes oft sehr gering ist, und einen gestreckten Körper.

Folgende Neubenennungen von Gattungen haben sich als notwendig erwiesen :

Pseudocistela Blackb. möge wegen Kollision mit der älteren Gattung gleichen Namens (C r o t c h) in Neocistela umgeändert werden. Atractus Lac. 1859. Der Name wurde vergeben 1828 von Wagler

für eine Reptiliengattung, 1833 von Laporte für eine Hemipterengattung, 1837 von A g a s s i z für eine Molluskengattung. Ich schlage Neoatractus vor.

Ismarus Haag 1878. Wurde 1835 von Hali da y für eine Proctotrupidengattung verwendet. Ich benenne die Gattung Simarus. Isotoma Blanch. 1845. Bereits 1839 von $\mathrm{Burl}$ für eine Thysanuride (Poduride) vergeben. Es möge Isocera dafür eintreten.

Plesia Klug 1833. 1807 benannte Jurin eine Thynnidengattung mit demselben Namen. Ich schlage vor, das Synonym Eubalia Cast. dafür einzusetzen.

Verschiedene Gattungen mufsten in andere Familien versetzt werden; aufser den neuen mögen hier noch die wenig bekannten alten Versetzungen kurz erwähnt werden.

Eubalia Cast. gehört zu den Alleculiden und ist sehr wahrscheinlich synonym mit Plesia Klug. Ich kann bei meinen Eubaliaund Plesia-Arten keinen generischen Unterschied entdecken.

(Fairm. Ann. Belg. 1897, p. 114; 1899, p. 539.)

Euomma Boh. ist Alleculide und synonym mit Apellatus. (Blackb.

Trans. R. Soc. S. Austr. 1891, p. 313.)

Lagrioida Fairm. ist nach $\mathrm{C}$ h a m p i o n, Ent. Monthly Mag. 1890, p. 120, Melandryide.

Ommatophorus ist nach Blackb. 1. c. p. 335 Alleculide (Cistelide) und Homotrysis aufserordentlich nahe. 


\section{$2 \mathrm{BHL}$ Biodiversity Heritage Library}

Borchmann, Fritz. 1909. "Systematische und synonymische Notizen über Lagriiden und Alleculiden (Col.)." Deutsche entomologische Zeitschrift 1909, 712-714.

View This Item Online: https://www.biodiversitylibrary.org/item/103377

Permalink: https://www.biodiversitylibrary.org/partpdf/245027

\section{Holding Institution}

Harvard University, Museum of Comparative Zoology, Ernst Mayr Library

\section{Sponsored by}

Biodiversity Heritage Library

\section{Copyright \& Reuse}

Copyright Status: Public domain. The BHL considers that this work is no longer under copyright protection.

This document was created from content at the Biodiversity Heritage Library, the world's largest open access digital library for biodiversity literature and archives. Visit BHL at https://www.biodiversitylibrary.org. 